\title{
In Situ Observation of the Four-step Dehydration Process of the $1 \beta$-Methylcarbapenem Antibiotic CS-834 Crystal by X-Rays
}

\author{
Katsuhiro Kobayashi, ${ }^{*, a, c}$ Hiroshi Fukuhara,${ }^{a}$ Tadashi Hata, ${ }^{b}$ and Yuji OHAshi ${ }^{c}$ \\ ${ }^{a}$ Process Development Laboratories, Sankyo Co., Ltd.; 1-12-1 Shinomiya, Hiratsuka, Kanagawa 254-8560, Japan: \\ ${ }^{b}$ Biomedical Research Laboratories, Sankyo Co., Ltd.; 1-2-58 Hiromachi, Shinagawa-ku, Tokyo 140-8710, Japan: and \\ ${ }^{c}$ Department of Chemistry and Materials Science, Tokyo Institute of Technology; 2-12-1 O-okayama, Meguro-ku, Tokyo \\ 152-8551, Japan. Received June 4, 2003; accepted August 22, 2003
}

The $1 \beta$-methylcarbapenem antibiotic CS-834 takes six crystalline forms depending on ambient conditions. The X-ray powder diffraction revealed that the dihydrate crystal (B2-form) was changed to the monohydrate (B1-form) through the intermediate form (B2'-form). The monohydrate form was then changed to the dehydrate (B0-form) through the intermediate B1'-form. The progress of the dehydration along the needle axis (c-axis) was observed under a microscope. When a single crystal of the B2-form was mounted on a diffractometer and the humidity was reduced, the crystal was gradually changed to the various dehydration forms with retention of the single crystal. The crystals of B2- to B0-forms form isostructures to each other except the solvent water molecules. In the crystal structure of the B1-form, the pivaloyloxymethyl moiety is disordered. One is nearly similar to that of the B2-form, while another is similar to that of the B0-form. Each crystal structure consists of a columnar arrangement of CS-834 along the $c$-axis, and the water molecules are located between the columns and form a characteristic hydrogen bond network. When the water molecules leave the crystal, the columns slide slightly following the slight conformational change in the pivaloyloxymethyl groups and are connected by another type of hydrogen bond network. Such a rearrangement of the hydrogen bond network should be a motive force of the phase change to the next step due to the dehydration. Since the hydrogen bond network extends along the $c$-axis, the dehydration proceeds along the $c$-axis as observed microscopically.

Key words hydrate; dehydration; $1 \beta$-methylcarbapenem antibiotic; single-crystal X-ray analysis; hydrogen bond system; crystal structure

Bulk drug substances frequently can be obtained as crystalline hydrates rather than as anhydrates, because they can crystallize more easily, ${ }^{1)}$ or are transformed into hydrates by contact with water molecules from hydrate excipients in the formulation process. ${ }^{2)}$ The hydrate crystals often transform into different solids such as amorphous or dehydrate form in the process of drying or storage under low relative humidity (RH). ${ }^{3-6)}$ Generally, the resulting dehydrate crystals can be converted to the different hydrate forms depending on the surrounding RH and temperature. It is also well known that different hydrate drugs show different physicochemical properties, ${ }^{7,8)}$ such as bioavailability, phase stability, and dissolution rate. For the development of pharmaceuticals using hydrous bulk drug substances, many efforts have been made to investigate the changes in the physicochemical properties in the process of phase transformation to different hydrate states. The prediction of hydration properties has therefore been a long-standing subject of great interest in pharmaceutical science.

A compound of pivaloyloxymethyl $(1 R, 5 S, 6 S)-6-[(R)-1-$ hydroxyethyl]-1-methyl-2-[[(R)-5-oxo-pyrrolidin-3-yl]thio]1-carbapen-2-em-3-carboxylate, CS-834, was developed as an orally effective $1 \beta$-methylcarbapenem antibiotic agent possessing potent and broad-spectrum antibacterial activities and excellent stability against dehydropeptidase-I (Fig. 1). ${ }^{9)}$

It crystallizes as an anhydrate form (A-form) from anhydrous solutions and as a dihydrate (B2-form) from an aqueous solution. The B2-form undergoes the multistep transformation following the loss of water molecules upon heating, as shown in Fig. $2 .{ }^{10)}$ This figure indicates that the B2-form is transformed to the dehydrate form ( $\mathrm{B} 0$-form) through the $\mathrm{B} 2^{\prime}$-, B1-, and $\mathrm{B} 1$ '-forms, where the $\mathrm{B} 1$-form was the mono- hydrate form whereas the $\mathrm{B} 2^{\prime}$ - and $\mathrm{B} 1^{\prime}$-forms were intermediate ones between the B2- and B1-forms, and between the $\mathrm{B} 1$ - and $\mathrm{B} 0$-forms, respectively. The possible crystal transformation of CS-834 is summarized in Fig. 3.

It was reported that the hydrate crystals of disodium adenosine $5^{\prime}$-triphophate $\left(\mathrm{Na}_{2} \mathrm{ATP}\right)$ and disodium cytidine $5^{\prime}$-monophophate $\left(\mathrm{Na}_{2} \mathrm{CMP}\right)$ also underwent reversible humidity-dependent structural transformation between the higher hydrate and the lower hydrate forms as observed by X-ray crystal structure analysis. ${ }^{11,12)}$ Here, we report the dehydration process of the hydrous crystal of CS-834, with the change in the RH and the structural changes in the transformation observed by single-crystal X-ray analysis.

\section{Experimental}

Preparation of Different Crystal Forms. Materials CS-834 of pharmaceutical grade was synthesized in the Process Development Laboratories of Sankyo Co., Ltd.

Preparation of the Dihydrate (B2-Form) The A-form crystals were dissolved in a $3 \%$ aqueous ethyl acetate solution at $40^{\circ} \mathrm{C}$. The solution was filtrated, evaporated, cooled to about $0^{\circ} \mathrm{C}$, and kept at $0{ }^{\circ} \mathrm{C}$ overnight. The crystals were collected by filtration and washed with $3 \%$ aqueous ethyl acetate. The crystals were kept at $25^{\circ} \mathrm{C}$ and under about $60 \% \mathrm{RH}$ for $3 \mathrm{~d}$.

Preparation of Single Crystals of the B2-, B2'-, B1-, and B0-Forms Single crystals of the B2-form were obtained from an aqueous ethyl acetate solution by slow evaporation. Single crystals of the B2'-, B1-, and B0-forms were obtained from the $\mathrm{B} 2$-form by keeping under the controlled conditions

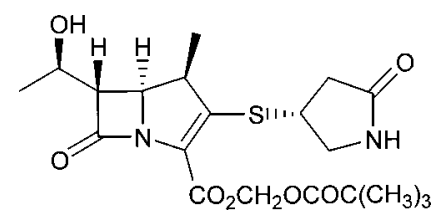

Fig. 1. Chemical Structure of CS-834 

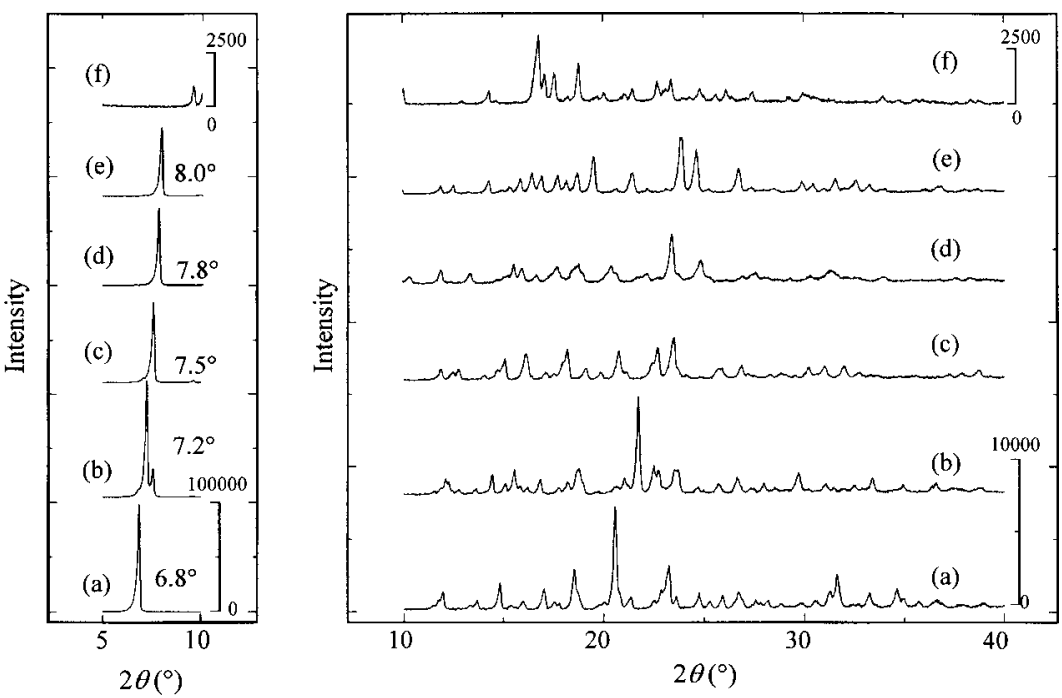

Fig. 2. Change in Powder X-Ray Diffraction Patterns upon Heating: (a) at $30^{\circ} \mathrm{C}(\mathrm{B} 2-\mathrm{Form}) ;$ (b) at $35^{\circ} \mathrm{C}\left(\mathrm{B} 2^{\prime}\right.$-Form); (c) at $50^{\circ} \mathrm{C}\left(\mathrm{B} 1\right.$-Form); (d) at $60^{\circ} \mathrm{C}$ (B1'-Form); (e) at $80^{\circ} \mathrm{C}\left(\mathrm{B} 0\right.$-Form); and (f) after Annealing at $120^{\circ} \mathrm{C}$

The measurement was performed at $25^{\circ} \mathrm{C}$ (A-form).

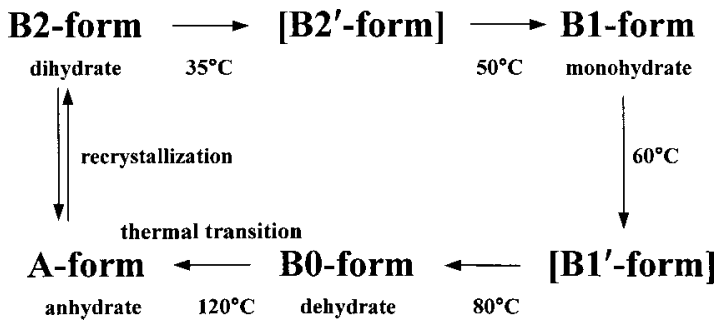

Fig. 3. Phase Interconversion with Preparation Conditions of Modifications of CS-834

as follows: the $\mathrm{B} 2{ }^{\prime}$-form, under less than $16 \% \mathrm{RH}$ at $25^{\circ} \mathrm{C}$; the $\mathrm{B} 1$-form, under $11 \% \mathrm{RH}$ at $20^{\circ} \mathrm{C}$; and the $\mathrm{B} 0$-form, under $0 \% \mathrm{RH}$ at $20^{\circ} \mathrm{C}$. Relative humidity was controlled using silica gel $(0 \% \mathrm{RH})$ and saturated aqueous solutions of $\mathrm{CaBr}_{2}(16 \% \mathrm{RH})$ and $\left.\mathrm{LiCl} \cdot \mathrm{H}_{2} \mathrm{O}(11 \% \mathrm{RH}) .{ }^{13}\right)$

Analytical Methods. Morphological Observation Optical microscopic observation were performed on a model AMX180 polarizing microscope with a rotating stage (Nikon Co., Ltd.). The B2-form single crystal was placed on a glass slide, and the slide was stored under $16 \% \mathrm{RH}$ at $25^{\circ} \mathrm{C}$. The size of the single crystal was $1.5 \times 0.2 \times 0.1 \mathrm{~mm}^{3}$.

Powder X-Ray Diffraction under Various RH Conditions Each sample was packed in a sample holder and the diffraction pattern was recorded on a model Rint 2200 diffractometer (Rigaku Denki Co., Ltd.) equipped with a Rigaku humidity controller. The diffraction data in the $2 \theta$ range of $3-40^{\circ}$ were measured using a scintillation counter with graphite-monochromated $\mathrm{Cu} K \alpha$ radiation $\left(40 \mathrm{kV}\right.$ and $40 \mathrm{~mA}$ ) with a scan step of $0.02^{\circ}$ and scan rate of $4 \% \mathrm{~min}$.

X-Ray Structure Determination of the Crystal Forms The X-ray diffraction measurements of the B2-, B1-, and B0-forms were carried out at $-50{ }^{\circ} \mathrm{C}$ on a Rigaku R-AXIS RAPID system equipped with an imagingplate scanner using graphite-monochromated $\operatorname{MoK} \alpha$ radiation. Unit cell parameters were obtained from least-squares refinement of the setting angles of reflections based on the data collected.

The X-ray crystal data of the $\mathrm{B} 2^{\prime}$-form were collected at $-100{ }^{\circ} \mathrm{C}$ in the $\omega-2 \theta$ scan mode with a four-circle X-ray diffractometer (Rigaku AFC-7R) using graphite-monochromated $\mathrm{Cu} K \alpha$ radiation. Unit cell parameters were refined with 20 reflections. The intensities were corrected for Lorenz and polarization effects.

The structures were solved by direct methods using program SIR97, ${ }^{14)}$ and full-matrix least-squares refinement on $F^{2}$ was completed using the program SHELEXL-97. ${ }^{15)}$ Nonhydrogen atoms were refined anisotropically. In the B2'-form, the oxygen atoms of water molecules were refined isotropically. In the B1-form, minor atoms in the disordered pivaloyloxymethyl group were also refined isotropically. As many hydrogen atoms as possible were located in the difference Fourier map. The positions of the remaining hydrogen atoms were assigned geometrically. All hydrogen atoms were refined isotropically. The experimental and crystallographic data are summarized in Table 1.

For the B1- and B0-forms, the intensity data were collected after many trials. However, the crystallinity was not satisfactory considering from the diffraction pattern. The diffraction spots were expanded and split. Although the integration area of each spot was expanded to include the whole spot, the $R$ merge factor became $15.1 \%$ and $15.3 \%$ for the $\mathrm{B} 1-$ and $\mathrm{B} 0$-forms, respectively. This caused the considerably high $\mathrm{R}$ values for the two crystal forms.

\section{Results}

Transformation Conditions from the B2-Form to Various Hydrate Forms To prepare single crystals of various hydrates, the transformation of crystalline powder of the B2form was investigated using humidity-controlled powder Xray diffractometry. The change in powder X-ray diffraction pattern is shown in Fig. 4. The B2-form was transformed to the $\mathrm{B} 2^{\prime}$-form under $20 \% \mathrm{RH}$ at $25^{\circ} \mathrm{C}$ for $10 \mathrm{~h}$ and to the B1form under $10 \% \mathrm{RH}$ at $25^{\circ} \mathrm{C}$ for $2 \mathrm{~h}$. The powder X-ray diffraction patterns of these samples were identical with those of the B2' - and B1-forms, respectively. However, the B1form could not be further transformed into the $\mathrm{B} 1^{\prime}$-form under $6 \% \mathrm{RH}$ at $25^{\circ} \mathrm{C}$ for 2 months.

The B2'-form produced instantly reverted to the B2-form under $\mathrm{RH}$ higher than $22 \%$ at $25^{\circ} \mathrm{C}$. The $\mathrm{B} 1$-form was transformed into the $\mathrm{B} 2$-form when the $\mathrm{RH}$ increased to more than $80 \%$ at $25^{\circ} \mathrm{C}$. The anhydrate crystal (A-form), however, was not transformed into any of the hydrates under RH of $40 \%$ to $80 \%$ for 1 month.

Morphological Change of the B2-Form Crystal Optical microscopy was used to observe the crystal transformation caused by the loss of water molecules from the B2-form. As shown in Fig. 5, the B2-form crystal became opaque, indicating dehydration of the B2-form. The opaque regions expanded from the $(001)$ and the $(00 \overline{1})$ faces, which are both ends of the needle, and then spread along the $c$-axis in both directions. Such an optical change should be closely related to the crystal structure.

Crystal Structures of the B2- and B2'-Forms The crystal structure of the $\mathrm{B} 2$-form at $23^{\circ} \mathrm{C}$ was determined previously. ${ }^{16)}$ To compare the crystal structure of the B2-form 

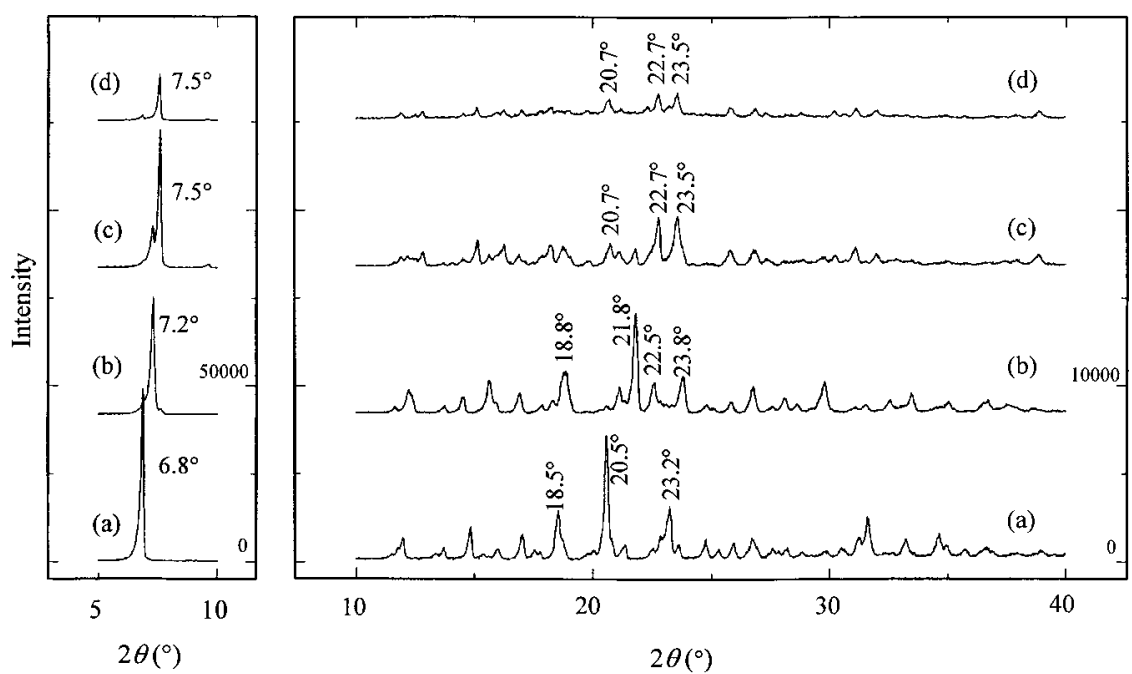

Fig. 4. Change in Powder X-Ray Diffraction Patterns of the B2-Form at Various RH Values at $25^{\circ} \mathrm{C}$ : (a) $30 \% \mathrm{RH}$, after $2 \mathrm{~h}$; (b) $20 \% \mathrm{RH}$, after $10 \mathrm{~h}$; (c) $10 \% \mathrm{RH}$, after $2 \mathrm{~h}$; (d) $6 \% \mathrm{RH}$, after 2 Months

The B2-form was transformed to the B2'-form under $20 \% \mathrm{RH}$ at $25^{\circ} \mathrm{C}$ for $10 \mathrm{~h}$. After storage under $10 \% \mathrm{RH}$ at $25^{\circ} \mathrm{C}$ for $2 \mathrm{~h}$, the B2-form was converted into the B1-form, which could not be further transformed under $6 \% \mathrm{RH}$ at $25^{\circ} \mathrm{C}$ for 2 months. The hydrate crystal forms were assigned to characteristic diffraction peaks, of which the values were: B2-form: $6.8,18.5$, and $23.2^{\circ}$; B2'-form: 7.2, 18.7, 21.7, 22.5, and 23.7 ; B1-form: 7.5, 20.7, 22.7, and 23.4 ${ }^{\circ}$; $1^{\prime}$-form: 7.8, 18.8, 20.4, and 23.4' ; and B0-form: 8.0, 19.5, 21.4, and $23.8^{\circ}$.

(a)

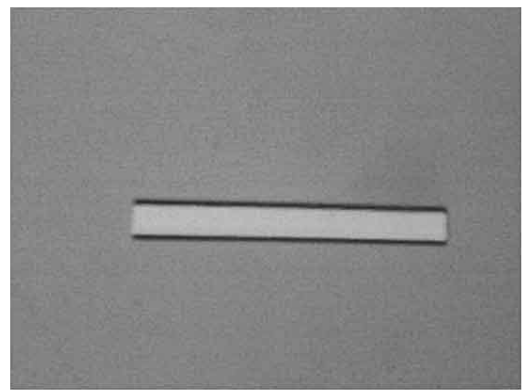

(c)

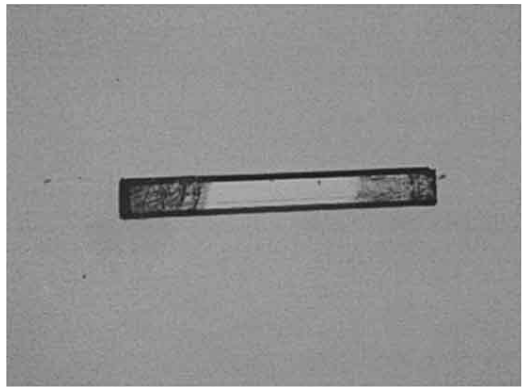

(b)

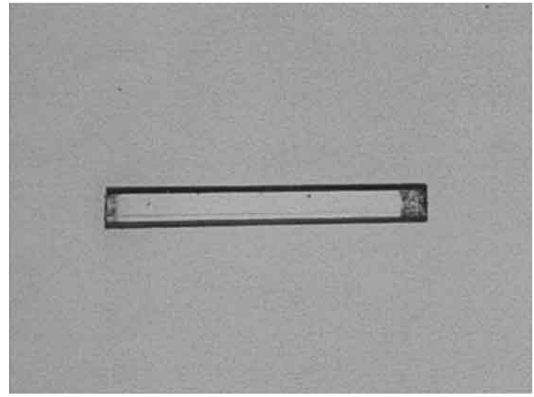

(d)

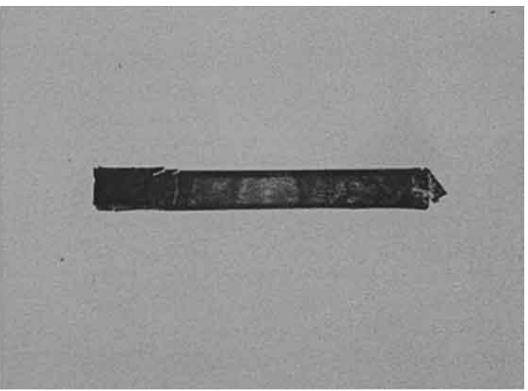

Fig. 5. Morphological Change of the B2-Form in Dehydration: (a) $0 \mathrm{~h}$; (b) $3 \mathrm{~h}$; (c) $12 \mathrm{~h}$; and (d) $2 \mathrm{~d}$

A single crystal of the B2-form was stored under approximately $16 \% \mathrm{RH}$ at $25^{\circ} \mathrm{C}$. The long axis of the needle crystal was parallel to the $c$-axis from the $\mathrm{X}$-ray structure analysis of the B2-form.

with those of other hydrates, the structure of the B2-form was determined at $-50^{\circ} \mathrm{C}$ using $\mathrm{X}$-ray structure analysis. The crystal data and the experimental details are summarized in Table 1. The molecular and crystal structures at $-50{ }^{\circ} \mathrm{C}$ are shown in Figs. 6a and 7a, respectively. A hydrogen bonding chain of water molecules is formed along the two-fold screw axis parallel to the $c$-axis, and the CS-834 molecules are hydrogen-bonded to the chain. The unit-cell dimensions of B2'-form changed significantly compared with those of the $\mathrm{B} 2$-form; the lengths of the $b$ - and $c$-axes length became $4.6 \%$ shorter and $3.9 \%$ longer than the corresponding ones of the B2-form, respectively. However, the $a$-axis changed little (only $1.0 \%$ shorter) after the transformation to the $\mathrm{B} 2$ '-form. The characteristic powder diffraction peak at $7.2^{\circ}$ corresponds to the (020) reflection. The molecular structure with atom numbering and the crystal structure are shown in Figs. $6 \mathrm{~b}$ and $7 \mathrm{~b}$, respectively. There are three types of water molecule per CS-834 molecule. The final occupancy factors of the disordered ones, $\mathrm{O} 31, \mathrm{O} 32$, and $\mathrm{O} 33$, were fixed at 0.22 , 0.22 , and 0.78 , respectively. The numbers of water molecules per CS-834 molecule in the B2'-form were 1.22 from occupancy parameters. The B2'-form had two types of hydrogen bond scheme because the distances of the O31-O33 atoms and the $\mathrm{O} 32-\mathrm{O} 33$ atoms were very short. The O31 and $\mathrm{O} 32$ 
Table 1. Experimental and Crystallographic Data

\begin{tabular}{|c|c|c|c|c|}
\hline Parameter & B2-form & $\mathrm{B} 2^{\prime}$-form & B1-form & B0-form \\
\hline Chemical form & Dihydrate & Intermediate form & Monohydrate & Dehydrate \\
\hline Formula & $\mathrm{C}_{20} \mathrm{H}_{32} \mathrm{O}_{9} \mathrm{~N}_{2} \mathrm{~S}_{1} \cdot 2 \mathrm{H}_{2} \mathrm{O}$ & $\mathrm{C}_{20} \mathrm{H}_{28} \mathrm{O}_{7} \mathrm{~N}_{2} \mathrm{~S}_{1} \cdot \mathrm{nH}_{2} \mathrm{O}$ & $\mathrm{C}_{20} \mathrm{H}_{30} \mathrm{O}_{8} \mathrm{~N}_{2} \mathrm{~S}_{1} \cdot 1 \mathrm{H}_{2} \mathrm{O}$ & $\mathrm{C}_{20} \mathrm{H}_{28} \mathrm{O}_{7} \mathrm{~N}_{2} \mathrm{~S}_{1}$ \\
\hline Formula weight & 476.56 & - & 458.53 & 440.51 \\
\hline Radiation used $(\AA)$ & $\operatorname{MoK} \alpha, 0.71069$ & $\mathrm{Cu} K \alpha, 1.5418$ & $\operatorname{MoK} \alpha, 0.71069$ & $\operatorname{MoK} \alpha, 0.71069$ \\
\hline Temperature $\left({ }^{\circ} \mathrm{C}\right)$ & -50 & -100 & -50 & -50 \\
\hline Size $\left(\mathrm{mm}^{3}\right)$ & $0.25 \times 0.65 \times 0.05$ & $0.30 \times 0.60 \times 0.10$ & $0.20 \times 0.50 \times 0.05$ & $0.15 \times 0.30 \times 0.03$ \\
\hline Crystal form, color & Needle, colorless & Needle, white & Needle, white & Needle, white \\
\hline Crystal system & Orthorhombic & Orthorhombic & Orthorhombic & Orthorhombic \\
\hline Space group & $P 2_{1} 2_{1} 2_{1}$ & $P 2_{1} 2_{1} 2_{1}$ & $P 2_{1} 2_{1} 2_{1}$ & $P 2_{1} 2_{1} 2_{1}$ \\
\hline \multicolumn{5}{|l|}{ Cell constant } \\
\hline$a(\AA)$ & $15.4185(7)$ & $15.23(1)$ & $14.815(2)$ & $14.792(4)$ \\
\hline$b(\AA)$ & $25.660(1)$ & $24.45(1)$ & $23.358(3)$ & $22.195(6)$ \\
\hline$c(\AA)$ & $6.0412(2)$ & $6.18(1)$ & $6.9825(6)$ & $6.685(1)$ \\
\hline$V\left(\AA^{3}\right)$ & $2390.1(2)$ & $2301(5)$ & $2416.3(4)$ & $2194.7(9)$ \\
\hline$Z$ & 4 & 4 & 4 & 4 \\
\hline Calcd. density $\left(\mathrm{g} / \mathrm{cm}^{3}\right)$ & 1.324 & - & 1.260 & 1.333 \\
\hline$\mu\left(\mathrm{mm}^{-1}\right)$ & 0.186 & 0.172 & 0.179 & 0.191 \\
\hline Absorption correction & Multi-scan & None & Multi-scan & Multi-scan \\
\hline$F(000)$ & 1016 & 1016 & 976 & 936 \\
\hline$R_{\text {int }}(\%)$ & 4.14 & 17.22 & 16.17 & 17.25 \\
\hline$\theta$ Range for data collection $\left(^{\circ}\right)$ & $1.59-27.48$ & $3.42-64.84$ & $1.74-27.47$ & $1.65-27.48$ \\
\hline Index range: $\min / \max$ & $-18 / 19,-33 / 33,-7 / 7$ & $0 / 17,0 / 28,-6 / 0$ & $-19 / 19,-30 / 30,-9 / 8$ & $-19 / 19,-27 / 28,-8 / 7$ \\
\hline Refinement method & Full-matrix $/ F^{2}$ & Full-matrix $/ F^{2}$ & Full-matrix $/ F^{2}$ & Full-matrix $/ F^{2}$ \\
\hline Restraints & 2 & 3 & 3 & 0 \\
\hline No. of reflections & 5350 & 2068 & 4697 & 4436 \\
\hline \multicolumn{5}{|l|}{ No. of reflections used } \\
\hline$\left(I_{0}>2 \sigma\left(I_{0}\right)\right)$ & 4993 & 1153 & 2070 & 2265 \\
\hline Parameters & 386 & 290 & 306 & 272 \\
\hline$R 1(\%)$ & 3.3 & 10.4 & 15.4 & 15.2 \\
\hline${ }_{\mathrm{w}} R 2(\%)$ & 7.5 & 28.7 & 37.7 & 36.8 \\
\hline Goodness of fit & 1.052 & 1.057 & 1.015 & 1.012 \\
\hline Weight scheme & $w=1 /\left[\sigma^{2}\left(F_{\mathrm{o}}^{2}\right)+\right.$ & $\begin{array}{l}w=1 /\left[\sigma^{2}\left(F_{\mathrm{o}}^{2}\right)+\right. \\
\left.\quad(01761 P)^{2}+74575 P\right]\end{array}$ & $w=1 /\left[\sigma^{2}\left(F_{\mathrm{o}}^{2}\right)+\right.$ & $w=1 /\left[\sigma^{2}\left(F_{\mathrm{o}}^{2}\right)+\right.$ \\
\hline & where $P=\left(F_{\mathrm{o}}^{2}+2 F_{\mathrm{c}}^{2}\right) / 3$ & where $P=\left(F_{\mathrm{o}}^{2}+2 F_{\mathrm{c}}^{2}\right) / 3$ & where $P=\left(F_{\mathrm{o}}^{2}+2 F_{\mathrm{c}}^{2}\right) / 3$ & where $P=\left(F_{\mathrm{o}}^{2}+2 F_{\mathrm{c}}{ }^{2}\right) / 3$ \\
\hline$\Delta \rho_{\max }, \Delta \rho_{\min }\left(\mathrm{e} \AA^{-3}\right)$ & $0.16,-0.19$ & $0.59,-0.36$ & $0.40,-0.47$ & $0.55,-0.43$ \\
\hline Extinction method & SHELXL & None & None & None \\
\hline Extinction coefficient & $0.0054(8)$ & - & - & - \\
\hline Diffractometer & R-AXIS RAPID & AFC-7R & R-AXIS RAPID & R-AXIS RAPID \\
\hline
\end{tabular}
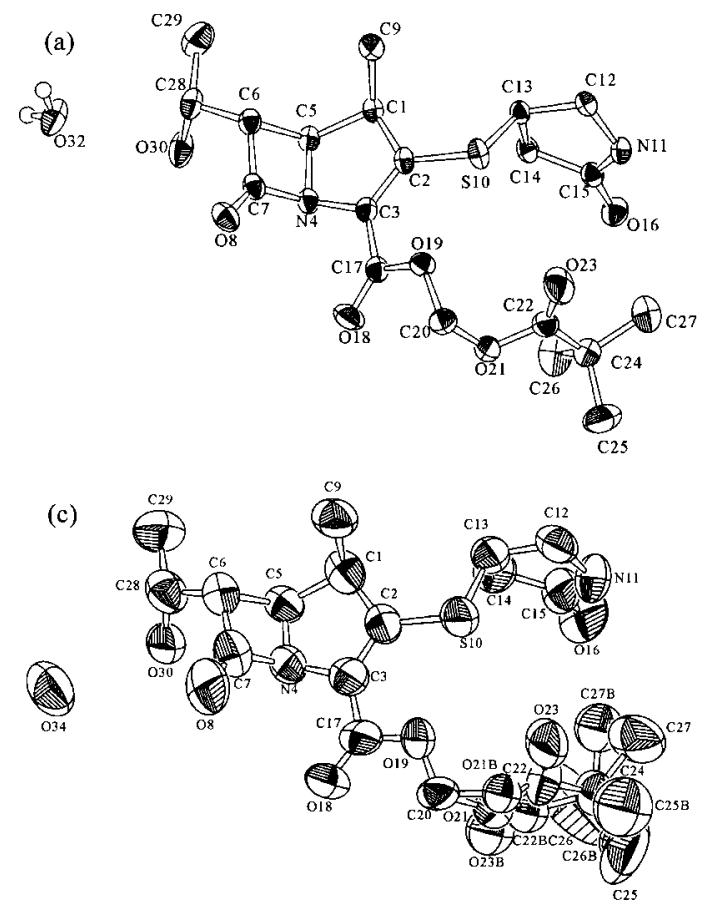

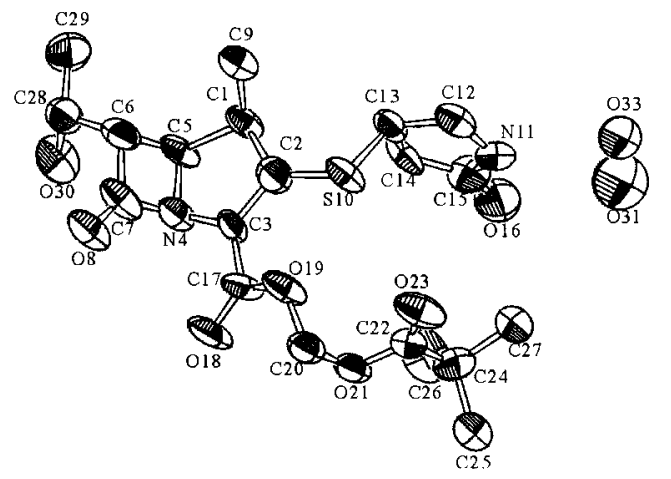

(d)

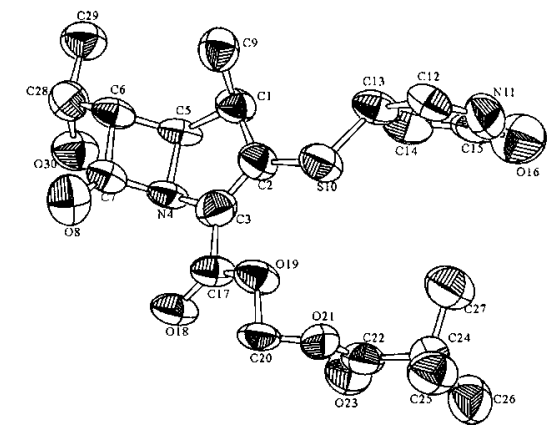

Fig. 6. Molecular Structures of CS-834 in Hydrates: (a) B2-Form; (b) B2'-Form; (c) B1-Form; and (d) B0-Form

Displacement ellipsoids are given at the $50 \%$ probability level. In the $\mathrm{B} 2$ '-form, the $\mathrm{O} 31-\mathrm{O} 33$ of water molecules were disorder and thus refined isotropically. The occupancy factor of each was: $\mathrm{O} 31,0.22 ; \mathrm{O} 32,0.22$; and $\mathrm{O} 33,0.78$. The $\mathrm{B} 1$-form was disordered with respect to the pivaloyloxymethyl moiety except for the $\mathrm{C} 24$ atom. The atoms in the major part corresponded to the $\mathrm{O} 21-\mathrm{C} 27$ atoms. The O21B-C27B atoms corresponded to the minor part. The occupancy factor of the major part was 0.69 . 
(a)

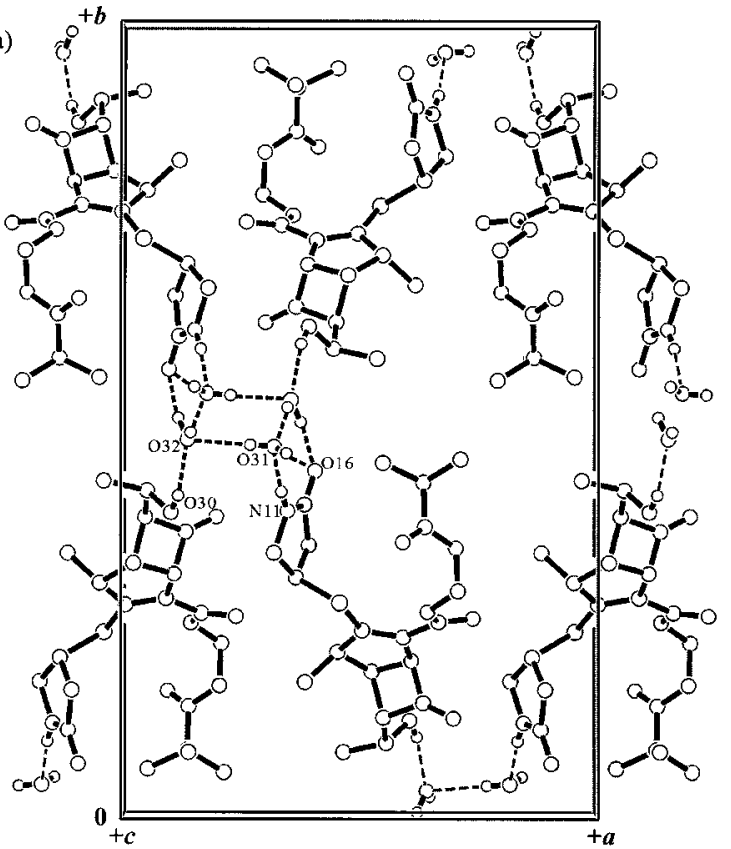

(c)

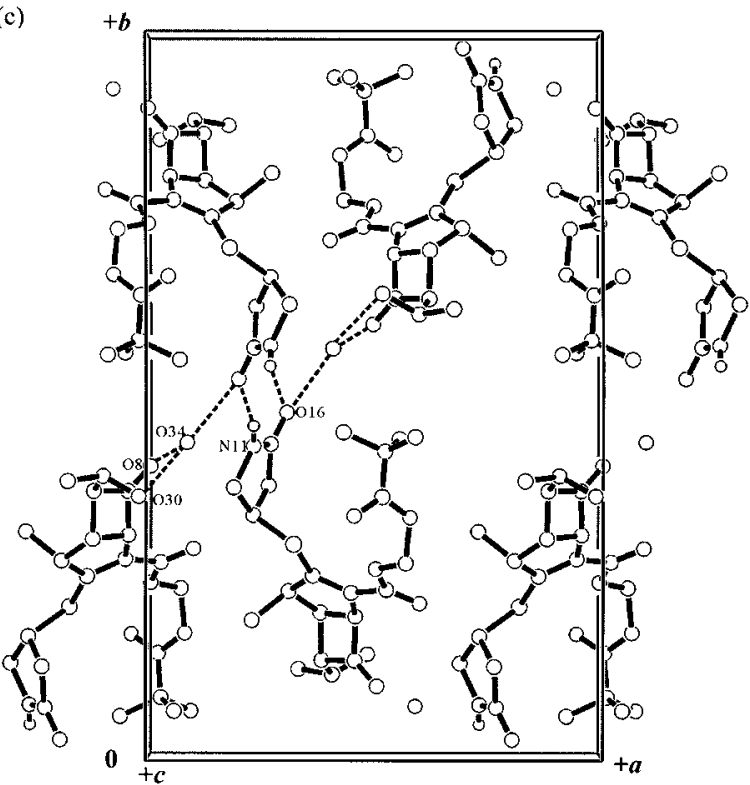

(b)

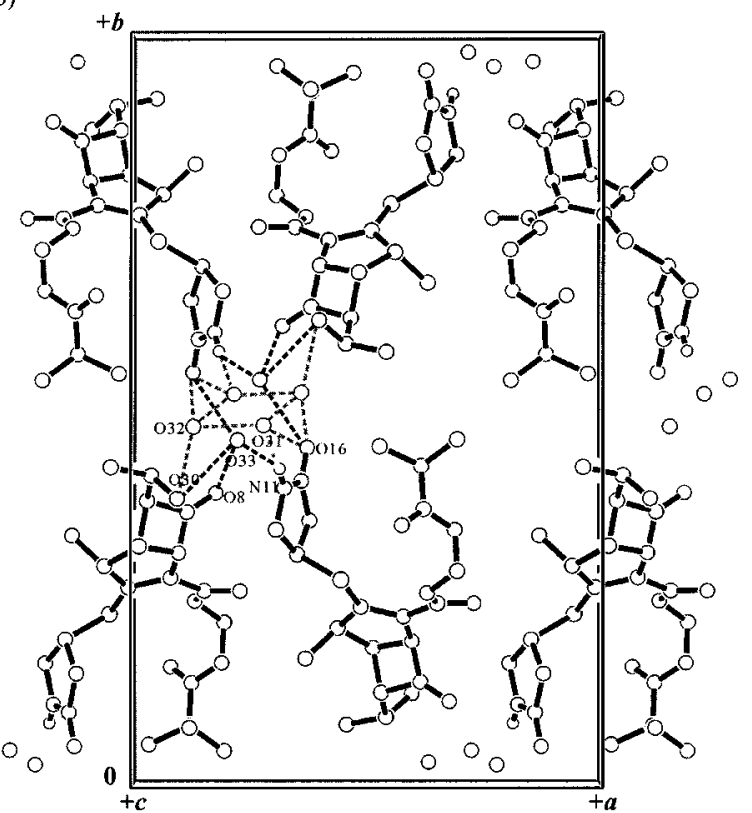

(d)

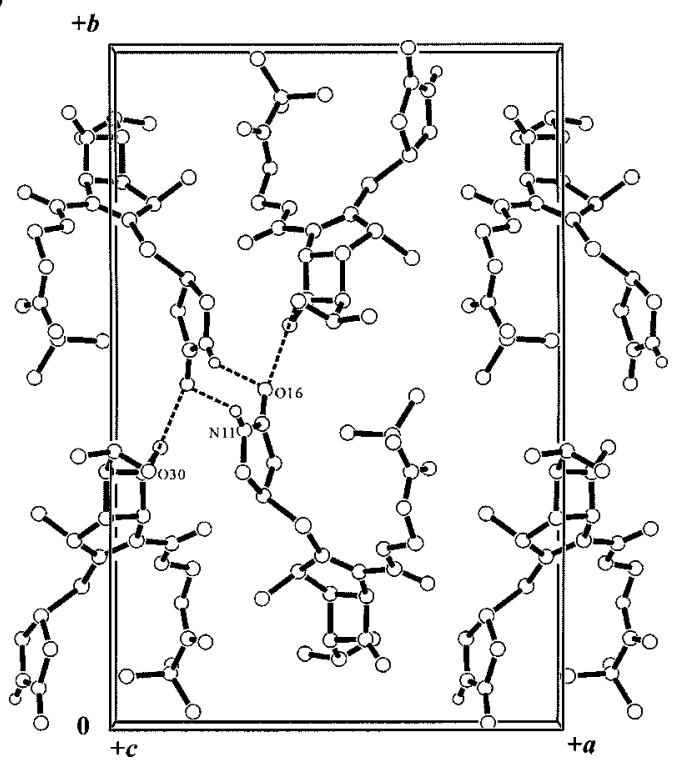

Fig. 7. Crystal Structures of the Hydrates Viewed along the $c$-Axis: (a) B2-Form; (b) B2'-form; (c) B1-Form; and (d) B0-Form

The dashed lines represent hydrogen bond interactions. In the B1-form, the crystal structure model of the major part is shown.

water molecules formed the same hydrogen bond scheme as the B2-form. It is obscure why such a hydrate form is stable and the reproducibility is maintained.

Crystal Structures of B1- and B0-Forms The unit-cell dimensions of the B1-form changed significantly from those of the B2-form; the lengths of the $a$ - and $b$-axes were $3.9 \%$ and $9.0 \%$ shorter than those of the B2-form, respectively, while the $c$-axis was $13.5 \%$ longer. This means that the $2 \theta$ value of the characteristic diffraction peak due to the $(020)$ reflection becomes $7.6^{\circ}$. The molecular and the crystal structures are shown in Figs. $6 \mathrm{c}$ and $7 \mathrm{c}$, respectively. The pivaloyloxymethyl group except for the $\mathrm{C} 24$ atom is disordered with the occupancy factors of 0.69 and 0.31 for the major and minor components, respectively. The hydrogen bonding forms a chain through the pyrrolidine amide moiety along the two-fold screw axis parallel to the $c$-axis.

The cell dimensions of the B0-form are similar to those of the $\mathrm{B} 1$-form; the lengths of the $a$ - and $b$-axes are $3.3 \%$ and $13.0 \%$ shorter than those of the B2-form, respectively, while the $c$-axis is longer by $11.1 \%$. The $2 \theta$ value of the characteristic diffraction peak due to the (020) reflection becomes $8.0^{\circ}$. The molecular structure and the crystal structure are shown in Figs. 6d and 7d, respectively. There is no peak corresponding to the solvent water molecule around the amide carbonyl group and the hydroxyl group in the difference Fourier map. There are two hydrogen bonds between the molecules.

Molecular Structure of CS-834 in Each Crystal Form The crystal structure of the A-form at $23{ }^{\circ} \mathrm{C}$ was reported previously. ${ }^{17)}$ The molecular and crystal structures are shown 
in Fig. 8. The molecular structures in various crystal forms were compared with each other, including the A-form. The conformation of the $\mathrm{C} 3-\mathrm{C} 17$ bond of the A-form is different from those of the hydrates and $\mathrm{B} 0$-forms. The torsion angle of N4-C3-C17-O19 of the A-form is 2.9(2) ${ }^{\circ}$, while those of the B2-, B2'-, B1-, and B0-forms are $-159.7(1)^{\circ}$, $-161.6(6)^{\circ},-174(1)^{\circ}$, and $-173.5(9)^{\circ}$, respectively. Such difference in the torsion angle is the reason why the A-form

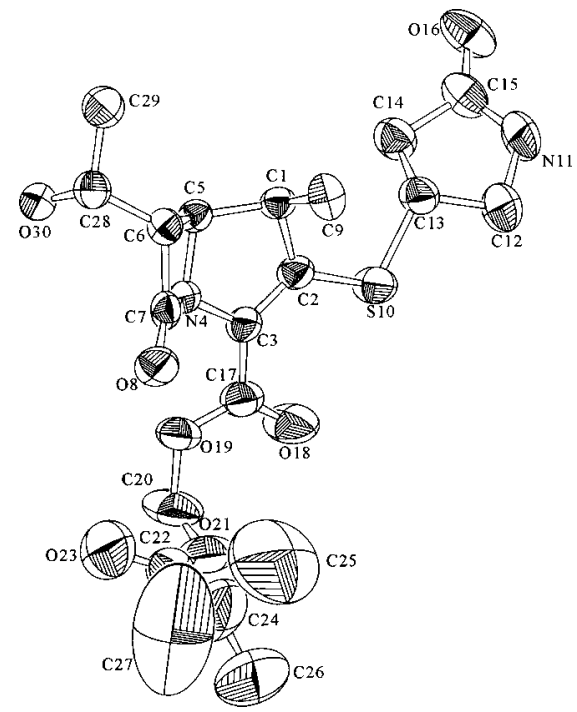

Fig. 8. Molecular Structures of CS-834 in the Anhydrate (A-Form) ${ }^{17}$ was not transformed into the B2-form even when stored under high RH for more than 1 month. The B1-form has two disordered conformations. The conformer with the major occupancy factor of 0.69 has a similar structure to that of the B2- or B2'-form, while the minor conformer is similar to that of the B0-form. The major conformer has a torsion angle of C22-O21-C20-O19 of $79(2)^{\circ}$, which is in accordance with the corresponding ones of the B2- and B2'-forms $\left[78.4(2)^{\circ}\right.$ and $79.8(8)^{\circ}$, respectively]. The same torsion angle of the minor conformer is $-77(3)^{\circ}$, which is in agreement with that of the B0-form of $-78(1)^{\circ}$. Thus the change in molecular conformation was also caused by dehydration after the disordered water molecule $\mathrm{O} 31$ and $\mathrm{O} 32$ completely leave the crystal. The cooperative motion of dehydration and conformational change probably makes it possible to maintain the single crystal form from the B2-form to the B0-form.

\section{Discussion}

Dehydration Process of the Dihydrate to the Dehydrate There is a characteristic hydrogen bond network in all crystal structures between the columnar arrangement of CS-834 and the water molecules. For example, the B2-form has an infinite hydrogen bond network composed of the two water molecules $\mathrm{O} 31$ and $\mathrm{O} 32$ along the two-fold screw axis parallel to the $c$-axis. Figure 9 is a schematic drawing of the molecules along the two-fold screw axis. The N11-H and carbonyl oxygen, O16, of the amide group and the O30 of the hydroxy group in the CS-834 molecule form hydrogen bonds with the

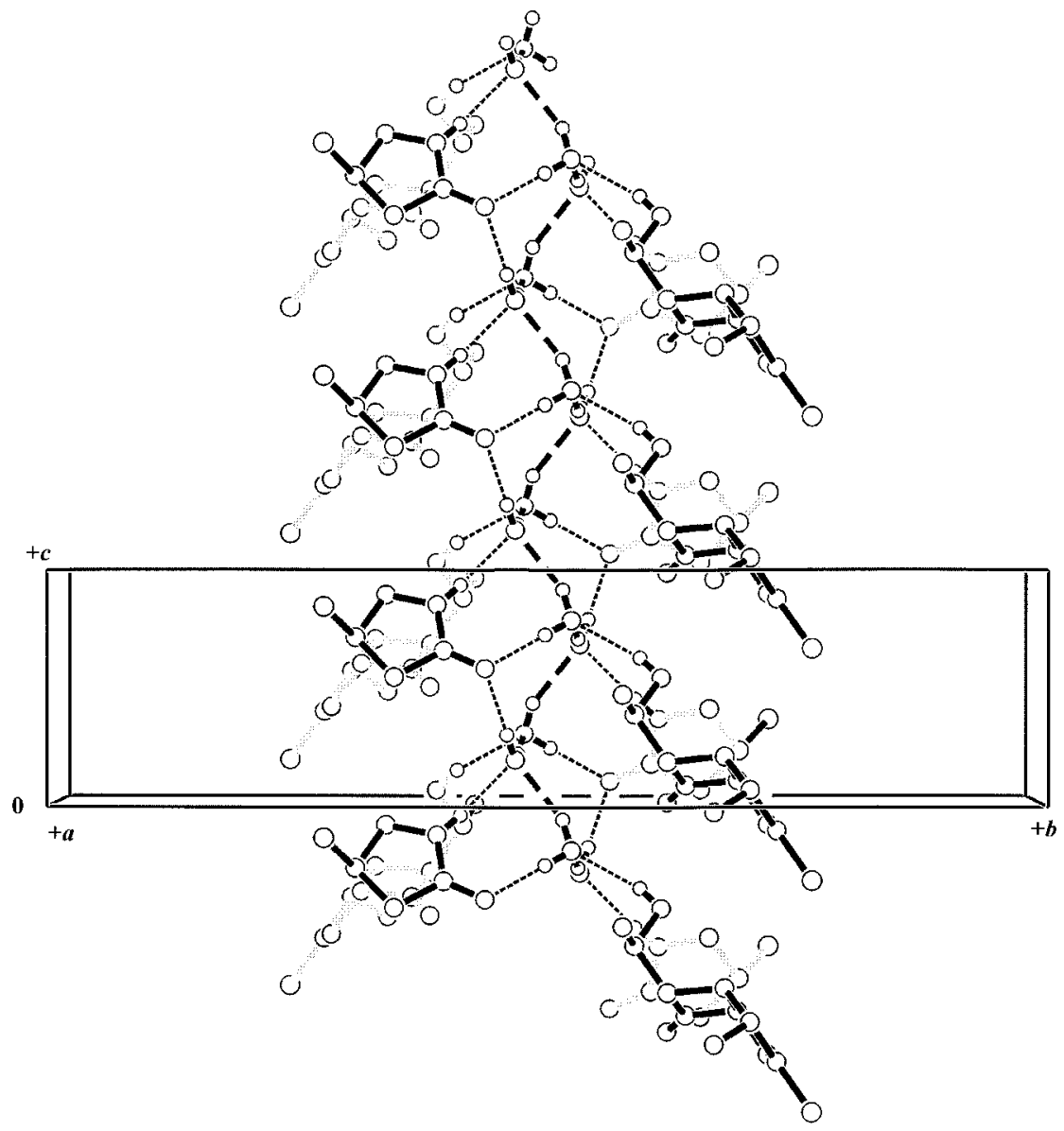

Fig. 9. Crystal Packing of the B2-Form along Two-Screw Axis

The functional groups with hydrogen bond interactions alone are represented to give a clear view in this figure. 
water network.

When the B2-form is transformed to the B2'-form, the minor component of $\mathrm{O} 31$ and $\mathrm{O} 32$ occupies a similar position to that observed in the B2-form and forms the same hydrogen bond network as that in the B2-form. On the other hand, the major component of $\mathrm{O} 33$ forms a hydrogen bond with N11. Moreover, it directly forms a hydrogen bond with $\mathrm{O} 16$ of one neighboring molecule and with $\mathrm{O} 8$ and $\mathrm{O} 30$ of the other neighboring molecule.

When the $\mathrm{B} 2{ }^{\prime}$-form is transformed to the $\mathrm{B} 1$-form, the disordered water molecules, $\mathrm{O} 31$ and $\mathrm{O} 32$, are completely lost. The columnar structure of CS- 834 molecules move to form a hydrogen bond for an interaction between the N11-H group and the $\mathrm{O} 16$ atom of the neighboring molecule. A hydrogen bond network is also formed along the two-fold screw axis along the $c$-axis. The $\mathrm{O} 16$ atom maintains the hydrogen bond with the water molecule $\mathrm{O} 34$ which has hydrogen bonds with $\mathrm{O} 30$ and $\mathrm{O} 8$.

When the $\mathrm{B} 1$-form is transformed to the $\mathrm{B} 0$-form, the water molecule $\mathrm{O} 34$ is completely lost. The $\mathrm{O} 30$ atom directly forms a hydrogen bond with $\mathrm{O} 16$. The hydrogen bond network along the two-fold screw axis is thus conserved. It was impossible to collect the intensity data of the $\mathrm{B} 1$ '-form, and it is difficult to assume the crystal structure between the B1- and B0-forms. The B1'-form may be a disordered structure composed of the $\mathrm{B} 1-$ and $\mathrm{B} 0$-forms, assuming that the $\mathrm{B} 1^{\prime}$-form is an intermediate structure as observed in the $\mathrm{B} 2{ }^{\prime}$ form. The reason why such intermediate structures as the $\mathrm{B} 2{ }^{\prime}$ - and B1' -forms are stable remains unresolved.

The CS-834 hydrates form a columnar structure along the $c$-axis. Since the B2-form crystal gradually became opaque along the $c$-axis from both edges of the crystal during the transformation to the $\mathrm{B} 2{ }^{\prime}$-form, the solvent water molecules may exit the crystal along the $c$-axis. The water molecules were located in the hydrophilic area composed of the amide and hydroxyl groups. Even if the water molecules were gradually released, the CS-834 and water molecules can form hydrogen bonds to develop a columnar structure along the $c$ axis, changing the partner of the hydrogen bonds. Since a similar hydrogen bond network along the two-fold screw axis is maintained in the dehydration process from the B2- to B0form, the crystalline lattice is considered to be conserved. It is clear that the conformational change in CS-834 plays an important role in maintaining the single crystal form.

\section{Conclusions}

The dehydration process of the CS-834 dihydrate crystal was examined using the X-ray powder diffraction method. Changing the RH or temperature, the dihydrate crystal B2form was transformed to the dehydrate B0-form through the B2'-, B1-, and B1'-forms, and the crystalline lattice was almost completely conserved. The B0-form returned to the B2form under more than $80 \% \mathrm{RH}$. Each structure was determined by single-crystal X-ray analysis at $-100{ }^{\circ} \mathrm{C}$ or $-50{ }^{\circ} \mathrm{C}$ except for the $\mathrm{B} 1^{\prime}$-form. It was impossible to obtain the $\mathrm{B} 1^{\prime}$ - form suitable for X-ray analysis. The four structures of the B2-, B2'-, B1-, and B0-forms are isomorphous, forming a columnar hydrogen bond network along the two-fold screw axis parallel to the $c$-axis, although the number of the solvent water molecules are different. Therefore these four structures are called pseudo-polymorphs. The anhydrate A-form has a different conformation from that of the B0-form. This explains why the A-form cannot be transformed to the B2-form even if maintained under very high RH.

The solvent water molecules occupy the hydrophilic area composed of the amide and hydroxyl groups. Even if the water molecules were gradually released, the CS-834 and water molecules can form hydrogen bonds to develop a columnar structure along the screw axis, changing the partner of the hydrogen bonds. The slight conformational change in the CS-834 molecule plays an important role in the recombination of the hydrogen bonds. The various hydration structures and the conformational change in the component molecule make it possible to retain the single crystal form and undergo a reversible process between the dehydration and hydration processes.

Acknowledgments The authors are grateful to Vice Professor Dr. Hidehiro Uekusa and Dr. Akiko Sekine of the Tokyo Institute of Technology for their constructive discussions and to Dr. Shuichiro Ito and Mr. Youji Furukawa of Sankyo Co., Ltd. for technical advice.

\section{References}

1) Vippagunta S. R., Brittain H. G., Grant D. J. W., Adv. Drug Del. Rev., 48, 3-26 (2001).

2) Kitamura S., Chang L., Guillory J. K., Int. J. Pharmaceut., 101, 127144 (1994).

3) Wang S. L., Lin S. Y., Chen T. F., Chem. Pharm. Bull., 48, 18901893 (2000).

4) Sheng J., Venkatesh G. M., Duddu S. P., Grant D. J. W., J. Pharm. Sci., 88, 1021-1020 (1999).

5) Leung S. S., Padden B. E., Munson E. J., Grant D. J. W., J. Pharm. Sci., 87, 508-513 (1998).

6) Kitaoka H., Wada C., Moroi R., Hakusui H., Chem. Pharm. Bull., 43, 649-653 (1995).

7) Shefter E., Higuchi T., J. Pharm. Sci., 52, 781-791 (1963).

8) Khankari R. K., Grant D. J. W., Thermchim. Acta, 248, 61-79 (1995).

9) Miyauchi M., Endo R., Hisaoka M., Yasuda H., Kawamoto I., J. Antibiot., 50, 429-439 (1997).

10) Kobayashi K., Fukuhara H., Kawamoto I., Hata T., Sekine A., Uekusa H., Ohashi Y., Chem. Pharm. Bull., 50, 1570-1573 (2002).

11) Sugawara Y., Kamiya N., Iwasaki H., Ito T., Satoh Y., J. Am. Chem. Soc., 113, 5440-5445 (1991).

12) Sugawara Y., Nakamura A., Iimura Y., Kobayashi K., Urabe H., J. Phys. Chem. B, 106, 10363-10368 (2002).

13) Stokes R. H., Ind. Eng. Chem., 41, 2013 (1949).

14) Altomare A., Burla M. C., Camalli M., Cascarano G. L., Giacovazzo C., Guagliardi A., Moliterni A. G. G., Polidori G., Spagna R., J. Appl. Crystallogr., 32, 115-119 (1999).

15) Sheldrick G. M., SHELXL-97, University of Goettingen, Germany, 1997.

16) Kobayashi K., Fukuhara H., Kawamoto I., Ito S., Hata T., Anal. Sci., 17, 357-358 (2001).

17) Kobayashi K., Fukuhara H., Kawamoto I., Furukawa Y., Hata T., Anal. Sci., 16, 555-556 (2000). 